\title{
COMPREENSÃO DA LEITURA E CONSCIÊNCIA TEXTUAL NOS ANOS INICIAIS
}

Vera Wannmacher Pereira ${ }^{1}$

\begin{abstract}
RESUMO
As dificuldades de compreensão da leitura nos anos iniciais são evidenciadas pelas diversas avaliações oficiais. Diante dessas evidências estatísticas e das obtidas por meio de pesquisas acadêmicas e de observações da atuação das crianças no cotidiano escolar, há o reconhecimento da situação como um problema que exige aprofundamento e busca de soluções. A Psicolinguística vem dando sua contribuição, especialmente no que se refere ao papel da consciência linguística no aprendizado da leitura. Muitos estudos vêm sendo realizados especialmente com foco na consciência fonológica. São encontrados também alguns, menos frequentes, sobre consciência sintática. Quanto ao papel da consciência textual, são poucas as iniciativas voltadas para os alunos dos anos iniciais. Isso faz com que a autora proponha como eixo para esta comunicação a consciência textual com apoio predominantemente em Gombert (1992), com o objetivo de examinar as relações entre esse nível de consciência e o aprendizado da leitura. Baseada em estudos recentes (PEREIRA; SCLIAR-CABRAL, 2012), a autora apresenta, nesta comunicação, primeiramente a análise do contexto de aprendizado e ensino da leitura. A seguir, desenvolve uma exposição teórica sobre aprendizado da leitura e consciência textual. Posteriormente, apresenta encaminhamentos pedagógicos para um ensino baseado no entrelaçamento desses dois tópicos. Ao final, desenvolve reflexões sobre a possibilidade de o caminho proposto contribuir para a solução do preocupante problema do aprendizado da leitura nos anos iniciais.
\end{abstract}

Palavras-chave: Aprendizado da leitura. Consciência textual. Anos iniciais. 


\section{INTRODUÇÃO}

As dificuldades de compreensão da leitura nos anos iniciais são evidenciadas pelas diversas avaliações oficiais. Diante dessas evidências estatísticas e das obtidas por meio de pesquisas acadêmicas e de observações da atuação das crianças no cotidiano escolar, há o reconhecimento da situação como um problema que exige aprofundamento e busca de soluções.

A Psicolinguística vem dando sua contribuição, especialmente no que se refere ao papel da consciência linguística na compreensão de textos. Muitos estudos vêm sendo realizados especialmente com foco na consciência fonológica. São encontrados também alguns, menos frequentes, sobre consciência sintática. Quanto ao papel da consciência textual, são poucas as iniciativas voltadas para os alunos dos anos iniciais. Isso faz com que a autora proponha como eixos para este artigo a consciência textual, com apoio predominantemente em Gombert (1992) e Dehaene (2001, 2007, 2009), e a compreensão de textos com alicerce especialmente em Goodman (1991) e Smith (2003), com o objetivo de examinar as relações entre ambas e propor encaminhamentos para seu ensino.

Baseada em estudos recentes (PEREIRA; SCLIAR-CABRAL, 2012), a autora apresenta primeiramente a análise do contexto de compreensão da leitura. A seguir, desenvolve uma exposição teórica sobre compreensão e consciência textual. Posteriormente, apresenta encaminhamentos pedagógicos para um ensino baseado no entrelaçamento desses dois tópicos. Ao final, desenvolve reflexões sobre a possibilidade de o caminho proposto contribuir para a solução do preocupante problema da compreensão de textos nos anos iniciais.

\section{CONTEXTO DA COMPREENSÃO DE TEXTOS NOS ANOS INICIAIS}

Não há como negar que o povo brasileiro vive grandes dificuldades para compreender textos simples próprios do seu cotidiano. Dados do INAF $^{2}$ (Índice de Alfabetismo Funcional) indicam a existência de, em 2009, na população de 15 a 64 anos, $7 \%$ de analfabetos, $21 \%$ de rudimentares, $47 \%$ no nível básico e apenas $25 \%$ no pleno. Além disso, evidencia-se que é pequena a redução das faixas mais baixas e o avanço das mais elevadas. 
Os dados sobre a escolaridade são ainda mais preocupantes, uma vez que inserem o ensino sistemático no problema. Nos anos iniciais, foco deste artigo, os dados não deixam dúvidas: $10 \%$ de analfabetos, $44 \%$ no nível rudimentar, $41 \%$ no básico e 6\% no pleno. Scliar-Cabral (2007, 2009) tem analisado esses dados, considerando a repercussão para a inserção do povo brasileiro na sociedade da informação.

Provas oficiais de âmbito nacional e estadual vêm evidenciando as condições não satisfatórias dos estudantes do Ensino Fundamental no que se refere ao manejo de materiais de leitura.

O SAEB ${ }^{3}$ tem avaliado alunos de $4^{a}$ e $8^{\underline{a}}$ séries do Ensino Fundamental e $3^{\text {a }}$ série do Ensino Médio. Os resultados da aplicação das provas têm apresentado índices abaixo dos desejados e estagnação nos desempenhos, sendo que, considerando a faixa de 0 a 325, de 1995 a 2005 os resultados dos alunos de $4^{\text {a }}$ série do EF são, sucessivamente, 188,3, 186,5, 170,7, 165,1, 169,4 e 172,3 Observe-se, pois, que, em relação ao ano de 1995, houve um rebaixamento nos resultados.

O SAERS ${ }^{4}$ tem também aplicou provas para avaliação das condições de leitura dos alunos da rede pública estadual de ensino, sendo que os dados de 2007, 2008 e 2009, em escala de 0 a 500, são, para a 5ª série, 202,4, 200,4, 207,5.

Como se vê, há efetivamente um sério problema no aprendizado da leitura. Os dados mais diversos levam a esse reconhecimento. Não há como negar. Não há como minimizar. Onde está a gravidade do problema? Especialmente em dois pontos. O primeiro está no fato de alguns alunos dos anos iniciais ainda serem analfabetos enquanto $85 \%$ se distribuem entre os níveis rudimentar e básico. 0 segundo ponto está nos estudantes universitários dos quais somente $68 \%$ atingem o nível pleno.

A preocupação com a situação se justifica. Com as crianças pequenas, pelos destinos sociais e culturais que se fecham para elas. E com os universitários por estarem entre eles os que se preparam para serem professores quando estará em suas mãos a condução de crianças e adolescentes estudantes.

A observação desses dados e dessas informações indica todas as séries como de potenciais necessidades. A escolha aqui, entretanto, é pelos anos iniciais ( $\left.3^{\circ} / 4^{\circ}\right)$, considerando sua natureza de transição entre a alfabetização inicial e os anos finais $\left(5^{\circ} / 9^{\circ}\right)$ do Ensino Fundamental. Tal condição situa essa faixa escolar como de 
especial relevância, dando continuidade a um processo de compreensão iniciado e preparando para o atendimento às expectativas de compreensão mais complexa nos anos finais.

Entre as diversas razões para a existência desse quadro está a das características do ensino desenvolvido. Trata-se de apenas uma delas, mas importante. Os estudos linguísticos que vêm sendo desenvolvidos disponibilizam sustentações teóricas que contribuem para análise do problema e proposição de caminhos linguístico-pedagógicos produtivos.

Neste artigo, esses apoios teóricos estão situados na consciência textual e na compreensão leitora, explicitados no tópico a seguir, com base na Psicolinguística em interface com Estudos do Texto.

\section{FUNDAMENTOS: COMPREENSÃO E CONSCIÊNCIA TEXTUAL}

A consciência humana vem sendo objeto de curiosidade popular e científica, gerando reflexões, convicções e definições ao longo dos tempos. No entanto, é de grande complexidade toda tentativa de caracterização de um estado consciente. As atitudes científicas do homem ou pelo menos em busca de entendimentos explicáveis têm produzido historicamente concepções possíveis para aquele momento, para aquele lugar.

As visões míticas buscam explicações culturais presentes no imaginário individual e social. Constitui-se em exemplo dessa perspectiva a explicação do mundo das ideias de Platão por meio do mito da caverna. De acordo com essa metáfora, o alcance da consciência abrange o domínio das coisas sensíveis (as sombras percebidas) e o domínio das ideias (as luzes da verdade). Essa consciência se realiza na libertação do homem, vivendo a dialética desses mundos. As filosóficas voltam-se para a essência humana, para o ser, para o âmago do homem, sendo a consciência considerada como aquilo que distingue o homem, que o define. As psicológicas direcionam suas investigações para a mente e atualmente para o cérebro. As neurocientistas colocam sua atenção no funcionamento do cérebro, ganhando espaço especial para sua investigação instrumentos tecnológicos diversos.

Constituem-se em importantes referências as concepções sobre consciência desenvolvidas por Baars (1993), Bachler (2006) e Dehaene (2009). 
Desenvolvida por Baars, tem-se a teoria do espaço global da consciência (global workspace), segundo a qual "os conteúdos conscientes estão contidos num espaço global: uma espécie de processador central usado para mediar a comunicação com um conjunto de processadores especializados não conscientes. Quando esses processadores especializados precisam transmitir informação para o resto do sistema, eles o fazem mandando informação para o espaço global que atua como uma espécie de quadro comunitário, acessível a todos os outros processadores." (TEIXEIRA, 1997).

Bachler (2006) apresenta as propriedades da consciência com base em Chafe: tem um foco circundado por informações que proporcionam um contexto, é dinâmica, tem um ponto de vista, necessita de uma orientação. Consiste no traço central da mente, o que significa que ela é indispensável para compreender qualquer processo cognitivo, sendo que sua estrutura intencional a vincula ao mundo. No caso da consciência sobre a linguagem, é fundamental a significação das palavras, das frases e dos discursos.

Dehaene (2009) relata que em seus experimentos evidencia-se o fato de que, apenas a partir do tempo de 270-300 milissegundos, é possível ver diferença entre o processamento consciente e o inconsciente. Isso ocorre a partir do momento em que diferentes áreas do cérebro entram em sincronia. Desse modo, a consciência não é realizada por uma área sozinha do cérebro, mas pela sincronia entre muitas regiões, a partir de um tempo de trabalho, conforme indicado acima.

Essas concepções de consciência (DEHAENE, 2001, 2007) são importantes para tratar especificamente da consciência linguística (SPINILLO; MOTA; CORREA, 2010). Pode ser então explicitada como apresentando as seguintes propriedades: ativa em sincronia diversas áreas do cérebro; tem um foco linguístico específico; utiliza informações periféricas a esse foco - o contexto; é intencional na busca da análise de algum ponto específico.

A consciência linguística, que aqui interessa especialmente por seu vínculo com a compreensão do texto, pode estar voltada para o conhecimento da própria linguagem em todos os modos de constituição e organização, estando predominantemente associada à memória declarativa e pode estar direcionada para o manejo desses elementos linguísticos, associando-se especialmente à memória procedimental. 
Nesse entendimento, a consciência linguística (GOMBERT, 1992) pode focar determinado segmento linguístico, considerando sempre o contexto dos demais segmentos. Essa condição faz com que ela seja categorizada de acordo com cada um desses segmentos em foco. A consciência fonológica tem como foco os fonemas (consciência fonêmica) e as sílabas (consciência silábica) que constituem a estrutura da língua e as propriedades entonacionais e rítmicas da língua em uso. Pode voltar-se para o segmento inicial, para o segmento medial ou para o segmento final. Pode ainda ter em vista processos de supressão, inserção, substituição, comutação, separação e junção.

A consciência morfológica tem como focos: o vocábulo - limites do seu começo e fim, a estrutura (constituintes lexicais e gramaticais), os processos flexionais (gênero, número, pessoa/número, tempo/modo) e os processos derivacionais. A consciência sintática direciona seu olhar para a frase internamente: seu limite (início e final da frase), estrutura da oração (constituintes e ordem), estrutura do período (constituintes e ordem), processos de construção (coordenação/subordinação/misto, paralelismo, combinações entre as palavras) e pontuação. A consciência léxicosemântica abrange o léxico mental, o significado e o sentido. O léxico mental está vinculado à memória lexical. O significado consiste na significação básica que os membros de uma mesma comunidade atribuem a uma palavra, incluindo a polissemia. Está arquivado na memória semântica. O sentido é a parte mais ativa no processo de leitura, consistindo numa construção ad hoc pelo leitor, dependendo do cruzamento entre texto, conhecimentos prévios e significação básica e estando associado à capacidade de inferências do leitor. A consciência pragmática volta-se para a situação de uso da língua - o texto é considerado do ponto de vista do enunciador/receptor, do objetivo, do suporte comunicativo, do momento e espaço da comunicação. A consciência textual focaliza 0 texto em suas relações textuais internas e suas relações com o contexto. Sendo essa consciência um dos eixos deste artigo, está mais densamente desenvolvida a seguir.

Conforme Gombert (1992), a consciência textual focaliza a superestrutura, a coerência e a coesão do texto.

A superestrutura envolve os traços que definem o texto como um determinado gênero, contribuindo para isso a situação comunicativa (autor, leitor, tempo, espaço, suporte) e o modo de organização - moldura, componentes constitutivos (unidades linguísticas), sequências dominantes - narrativa, descritiva, argumentativa, injuntiva, 
expositiva (ADAM, 2008), traços linguístico-estruturais (próprios dos diversos planos linguísticos).

A coerência se refere predominantemente ao conteúdo e suas relações internas e com o entorno, que podem ser explicitadas com base em Charolles (1978) - a manutenção do tema, indicando que o texto deve girar em torno de um eixo temático; a progressão do tema, indicando que o tema, embora precisando ser mantido, deve, ao mesmo tempo, progredir, avançar, se desenvolver; a ausência de contradição interna, indicando que não pode haver contradições temáticas ou linguísticas (emprego dos tempos e das pessoas verbais); a relação com o mundo, indicando que as afirmações têm que ter vínculo com a realidade - de verdade no caso do texto não ficcional e de verossimilhança no caso do texto ficcional.

A coesão consiste nos liames linguísticos do texto que contribuem para sua amarração e, assim, para a construção de seus sentidos. Apresenta-se em duas dimensões - a coesão lexical e a coesão gramatical (HALLIDAY; HASAN, 1976).

A coesão lexical realiza-se por meio de relações entre vocábulos lexicais substantivos, adjetivos e verbos. Essas relações constituem-se em um conjunto de regras: repetição de palavra - com frequência ocorre com o substantivo quando se constitui em palavra-chave; sinonímia ou quase-sinonímia - consiste na substituição vocabular para o mesmo referente, evitando a repetição excessiva e favorecendo a evolução do conteúdo; superordenado - estabelece relação de inclusão entre hiperônimo e hipônimo; associação por contiguidade - consiste na aproximação de vocábulos de um mesmo campo semântico.

A coesão gramatical ocorre por meio de relações entre vocábulos gramaticais preposição, conjunção, advérbio, pronome, artigo, numeral. Essas relações se expressam em um conjunto de regras: referenciação - retomada de elemento linguístico (referente) por meio de pronomes (referência); elipse - retomada vazia de um referente, podendo ser de uma palavra, de um segmento, de uma frase, de um parágrafo...; conjunção - relação de conexão estabelecida por elementos gramaticais: de adição, de tempo, de causa, de oposição, de continuidade.

Tendo a consciência textual como ponto de atenção o texto, é preciso ter presente que ele é organizado em planos linguísticos que se inter-relacionam e se amarram - o fônico, o morfológico, o sintático, o léxico-semântico, o pragmático e o textual. Desse modo, a observação da superestrutura, da coerência e da coesão implica a observação de todos esses planos e de todas as unidades linguísticas 
constitutivas do texto. Isso significa que a consciência textual direciona sua atenção para a superestrutura, a coerência e a coesão, mas no trânsito por todos os planos linguísticos e as unidades que os constituem.

Considerando a natureza da consciência textual, acima explicitada, e da compreensão leitora como processamento cognitivo, como exposto a seguir, evidenciam-se seus vínculos.

Nessa acepção, ler significa compreender (COLOMER; CAMPS, 2002), sendo para isso necessário realizar fundamentalmente dois processamentos simultâneos bottom-up e top-down (SCLIAR-CABRAL, 2008, 2009).

O processamento bottom-up caracteriza-se como ascendente, fazendo 0 movimento da informação textual em direção à cognição. Constitui-se numa leitura, minuciosa, vagarosa, em que todas as pistas visuais são utilizadas. É um processo de análise e de síntese em que, após o reconhecimento da palavra escrita, vão sendo construídos os sentidos, gradativamente, de palavras, frases, orações, até a macroestrutura, graças ao cruzamento com as informações provindas do processamento top-down.

O processo top-down caracteriza-se como um movimento que provém dos conhecimentos prévios armazenados nas várias memórias, sejam eles linguísticos, ou extralinguísticos, baseando-se na concepção antecipatória da leitura, segundo a qual são utilizadas simultaneamente as informações linguísticas do texto e os conhecimentos prévios do leitor.

Em ambos os tipos de processamento, mas especialmente no top-down, esses conhecimentos já armazenados pelo leitor assumem papel importante, na medida em que guiam os olhos do leitor na busca das pistas e encaminham as inferências durante o processo de leitura.

Os conhecimentos prévios não se constituem em elementos soltos no cérebro. Estão organizados em redes hierarquizadas que se conectam internamente e entre si - os esquemas cognitivos. São tais representações armazenadas na memória de longo prazo que interagem com o que está escrito no texto, permitindo ao leitor preencher os vazios que ali estão e chegar à compreensão. Isso significa que a dificuldade de compreensão pode estar vinculada à ausência de esquemas cognitivos consistentes ou a dificuldades no uso de procedimentos para ativá-los. Esse fato pode afastar o aluno da leitura, não gerando a construção de novos esquemas. Trata-se de uma situação circular que precisa ser rompida, sendo 
certamente o próprio processo de leitura, ao lado da diversidade de experiências, o caminho para o estabelecimento desses esquemas e, consequentemente, do desenvolvimento da compreensão leitora.

O processo cognitivo de leitura se altera (GOODMAN, 1991), a partir de algumas variáveis: objetivo da leitura, conhecimento prévio do conteúdo, condições de produção do texto, tipo de texto e estilo cognitivo do leitor. Tais variáveis determinam o processo de leitura - ascendente ou descendente. Smith (2003) considera que a informação não visual é de grande importância, uma vez que o significado, que é indispensável para o leitor, está não só nas marcas deixadas pelo autor no texto, mas nos conhecimentos prévios sobre o assunto e sobre a linguagem que o leitor traz e que podem fazê-lo perceber determinados aspectos do texto.

Nesse sentido, os dois movimentos são utilizados pelo leitor, dependendo da situação que se apresenta durante a leitura, envolvendo o próprio texto, o objetivo da leitura e o leitor (conhecimentos prévios, motivação, estilo cognitivo). O sucesso do desempenho na compreensão da leitura está na escolha do processo mais eficiente para dar conta dessa situação, em que variáveis se inter-relacionam e influenciam as decisões do leitor.

O processamento cognitivo da leitura ocorre através de dois grupos básicos de estratégias: cognitivas e metacognitivas. As cognitivas caracterizam-se pelos traços intuitivo e inconsciente, enquanto as metacognitivas caracterizam-se pela consciência, pela intenção de monitoramento do próprio processo. Constituem-se em estratégias cognitivas pressuposições intuitivas do leitor, como a de que a escrita, em nossa cultura, ocorre da esquerda para a direita. Constituem-se em estratégias metacognitivas situações de monitoramento do processo com o objetivo de garantir a compreensão, tais como: a definição e o controle do objetivo da leitura, a identificação de segmentos importantes, a distribuição da atenção, a avaliação da qualidade da compreensão e a tomada de medidas corretivas. O exame dessas estratégias expõe os elementos que internamente as constituem e que estão distribuídos nos planos constitutivos da língua - fônico, mórfico, sintático, semântico e pragmático.

A revisão de literatura sobre o assunto indica a existência de um conjunto de estratégias acionadas durante a leitura (PEREIRA, 2006), entre elas: skimming (leitura rápida e global do texto); scanning (leitura rápida em busca de alguma informação específica); predição (leitura antecipatória); leitura detalhada (leitura 
minuciosa); inferência (leitura dedutiva com base em dados do texto, do contexto e dos conhecimentos prévios do leitor); automonitoramento (acompanhamento da própria leitura), autoavaliação (verificação da produtividade da própria leitura) e autocorreção (alteração da própria compreensão).

Considerando os fundamentos aqui expostos, desenvolver a compreensão da leitura na sala de aula supõe assumi-la como processo cognitivo que utiliza estratégias de leitura, o que exige dar um lugar especial ao funcionamento linguístico do texto e à consciência do leitor sobre ele, isto é, à sua consciência textual.

Nesse entendimento, são feitos encaminhamentos para o ensino no tópico a seguir.

\section{ENCAMINHAMENTOS PARA O ENSINO DA LEITURA - COMPREENSÃO E CONSCIÊNCIA TEXTUAL}

$\mathrm{Na}$ concepção aqui exposta, o desenvolvimento da compreensão leitora está vinculado ao desenvolvimento da consciência textual do aluno (PEREIRA, 2010), o que supõe a reflexão sobre a linguagem do texto no que se refere à estrutura, à coerência e à coesão, com apoio em suas pistas fônicas, mórficas, sintáticas, semânticas, pragmáticas e textuais deixadas pelo autor no texto, confrontando-as com os conhecimentos prévios armazenados na memória declarativa, e da consciência procedimental do aluno, o que supõe a reflexão sobre o próprio processo de leitura realizado (GOMBERT, 1992; SMITH, 2003).

Desse modo, é importante a construção de um paradigma de ensino que considere os pontos a seguir.

a) A compreensão textual e o seu processamento cognitivo são marcados pela situação de leitura. Daí a importância de o professor ter critérios claros para a seleção do texto, considerando suas características e as da situação em que está imerso, os propósitos pedagógicos do ano escolar considerando a hierarquização definida pela escola, os objetivos de leitura e os conhecimentos prévios dos alunos.

b) A compreensão do texto tem suporte nos seus elementos linguísticos, isto é, nos constituintes fônicos (ritmo, rima, aliteração...), morfológicos (limite e estrutura dos vocábulos, classes gramaticais, flexões...), sintáticos (limite e estrutura das frases/versos, paralelismo, combinações entre os segmentos...), léxico-semânticos 
(vocábulos e seus significados, paralelismo...), pragmáticos (relações entre o texto e a situação comunicativa) e textuais (estrutura, coerência e coesão). Desse modo, cabe ao professor propor atividades de análise linguística cuidadosa do texto, pois essa alavanca seu entendimento, alicerça o trabalho de compreensão. Isso significa que esse trabalho deve ser simultâneo a ela, pois lhe dá condições de acontecer.

c) Os conhecimentos prévios armazenados na memória declarativa são acionados pelo leitor para a compreensão do texto. Isso significa que cabe ao professor, paralelamente ao trabalho de ensino da análise linguística, propor atividades que estimulem o aluno a acionar seus conhecimentos prévios, colocandoo diante de textos que têm maior ou menor correspondência com eles.

d) A consciência textual resulta da atenção dirigida para a estrutura, a coerência e a coesão do texto, com apoio nos elementos fônicos, morfossintáticos, léxico-semânticos, pragmáticos e textuais. Há que considerar que, ao chegar à escola, os alunos já possuem muitos conhecimentos intuitivos sobre a língua. Um aprendizado produtivo exige, no entanto, o desenvolvimento da consciência sobre eles. É o que faz transformar os conhecimentos espontâneos em conhecimentos científicos, cabendo salientar que é para isso que as crianças vão para a escola. É, assim, tarefa do professor propor atividades de ensino da leitura em que a atenção do aluno seja dirigida para os elementos linguísticos do texto, não apenas no sentido de seu uso, mas no sentido de sua explicação, da justificação do seu funcionamento, sendo, para isso, de grande importância os dados já armazenados na memória declarativa.

e) A consciência textual necessita também, para sua plenitude, do direcionamento da atenção para o processo de compreensão desenvolvido pelo leitor. Nesse sentido, é necessário que o professor proponha atividades que exijam do aluno a observação e a explicitação dos procedimentos de compreensão por ele utilizados, sendo para isso importante o uso da memória procedimental.

f) O processo de leitura prepara o processo de escrita. Desse modo, a escrita deve ser realizada no mesmo gênero textual lido, uma vez que as atividades de desenvolvimento da consciência textual, se realizadas no texto do gênero $A$, devem encaminhar para a escrita de texto do gênero A (PEREIRA, 2010b). Cabe então ao professor propor atividades de ensino da leitura em que o exame das marcas linguísticas do texto seja favorecedor do desenvolvimento da consciência textual do leitor (SMITH, 2003). 
Os pontos aqui apresentados podem ser considerados relevantes para um paradigma de ensino da leitura nos anos iniciais que valorize as relações entre consciência e compreensão/processamento textual.

\section{COMENTÁRIOS FINAIS}

Ao fechar este artigo, cabe a realização de alguns comentários sobre o tema que o norteou - compreensão e consciência textual nos anos iniciais. Esses comentários abrangem a escolha teórica e a perspectiva de ensino proposta, em seus pontos essenciais.

Os fundamentos teóricos utilizados indicam a existência de relações entre a compreensão da leitura de texto e a consciência textual. A primeira, definida com base em Goodman (1991) e Smith (2003), se realiza como processamento cognitivo, que, por sua vez, conta com o uso de estratégias cognitivas e metacognitivas de leitura. A segunda consiste na observação, pelo próprio leitor, dos constituintes linguísticos do texto e do processo de compreensão por ele realizado.

Segundo Gombert (1992), a consciência textual focaliza a superestrutura do texto, a coerência e a coesão. Há que ressaltar, no entanto, que esse nível de consciência, por ter o texto como objeto de observação, necessita transitar por todos os planos linguísticos e suas correspondentes unidades constituintes - os fonemas, os morfemas, os vocábulos, as frases e os próprios textos.

Isso significa que, para o desenvolvimento da consciência textual e da compreensão leitora nos anos iniciais, é necessário que o professor encaminhe atividades de observação da superestrutura, da coerência e da coesão do texto, considerando os entrelaçamentos com os elementos constitutivos fonológicos, morfológicos, sintáticos, semânticos e pragmáticos. Ao mesmo tempo deve propor a observação, pelos alunos, dos seus próprios processos realizados no trajeto da compreensão textual.

A perspectiva teórica e metodológica evidenciada neste artigo, com apoio na Psicolinguística em interface com os Estudos do Texto, consiste numa contribuição para o desenvolvimento da compreensão leitora de alunos dos anos iniciais e, desse modo, para a superação das dificuldades evidenciadas pelas provas oficiais de avaliação das condições de leitura desses estudantes. 


\section{NOTAS}

1 Doutorado em Letras - Linguística Aplicada. Pós-doutorado em Psicolinguística. Professora e pesquisadora da Faculdade de Letras da Pontifícia Universidade Católica do Rio Grande do Sul. Email: vpereira@pucrs.br.

${ }^{2}$ Disponível em: <http://www.ipm.org.br/ipmb_pagina.php?mpg=4.03.00.00.00\&ver=por $>$. Acesso em: 20 dez. 2011.

${ }^{3}$ Sistema de Avaliação de Educação Básica.

${ }^{4}$ Sistema de Avaliação do Rendimento Escolar do Rio Grande do Sul.

\section{READING COMPREHENSION AND TEXTUAL CONSCIOUSNESS ON PRIMARY SCHOOL}

The difficulties on reading comprehension in the primary school are evidenced by several official exams applied. Given these statistics and the evidences obtained through academic research and observations on children's performance during the school life, there is acknowledgment of the situation as a problem that requires further development and finding solutions. The Psycholinguistics is giving its contribution, especially regarding the role of linguistic consciousness on reading learning. Many studies have been conducted specifically focusing on phonological consciousness. Studies on syntactic consciousness are also found, although less than phonological ones. Regarding the role of textual consciousness, few initiatives considers the students of the primary school. This makes the author proposes as the heartland of this communication the textual consciousness with support predominantly on Gombert (1992), aiming to examine the relationship between this level of consciousness and learning to read. Based on recent studies (PEREIRA; SCLIAR-CABRAL, 2012), the author presents in this paper: a) the analysis of the context of learning and teaching of reading; b) a theoretical exposition about reading learning and textual consciousness; c) the pedagogical referrals for education based on the interaction between these two topics; and d) the development of reflections on the possibility of the proposed path contribute to the solution of the worrying problem on read learning by the primary schools students.

Keywords: Reading comprehension. Textual consciousness. Primary school. 


\section{REFERÊNCIAS}

ADAM, Jean-Michel. A linguística: introdução à análise textual dos discursos. São Paulo: Cortez, 2008.

BAARS, Bernard J. A cognitive theory of consciousness. Cambridge: Cambridge Univ., 1993.

BÄCHLER, Rodolfo. Conciencia y lenguaje: análisis del vínculo proyectado através de la intencionalidad. Rev GU, v. 2, n. 4, p. 432-438, 2006.

CHAROLLES, Michel. Introduction aux problèmes de la cohérence des textes. Langue Française. Paris: Larousse, n. 38, p. 7-41, mai 1978.

COLOMER, T.; CAMPS, A. Ensinar a ler e ensinar a compreender. Porto Alegre: Artes Médicas, 2002.

DEHAENE, Stanislas. The cognitive neuroscience of consciouness. Cambridge, Massachussetts: The MIT Press, 2001.

DEHAENE, Stanislas. Les neurones de la lecture. Paris: Odile Jacob, 2007.

DEHAENE, Stanislas. Signatures of consciousness : a talk by Stanislas Dehaene. Edge in Paris, 2009. Entrevista concedida a Edge Foundation. Disponível em: $<$ http://www.edge.org/3rd_culture/dehaene09/dehaene09_index.html>. Acesso em: 15 jul. 2010.

GOMBERT, Jean Émile. Metalinguistic development. Chicago: The University of Chicago Press: 1992.

GOODMAN. Kenneth S. Unidade na leitura: um modelo psicolinguístico transacional. Letras de Hoje, Porto Alegre, n. 86, p. 9-43, dez. 1991.

HALLIDAY, M. A. K.; HASAN, R. Cohesion in English. London: Longman, 1976.

PEREIRA, Vera Wannmacher. Computer-based learning of reading and writing im Elementary School. In: CESTARI, M. L.; MASSAGERO, E.; TONNESSEN, E. Netwarking cultures: Brazilian-Norwegian dialogues on education and culture. Norway: Portal Ebooks, 2006. p. 107-18.

PEREIRA, Vera Wannmacher. Aprendizado da leitura e consciência linguística. In: IX ENCONTRO DO CELSUL, 2010, Palhoça, SC. Anais... Palhoça: Universidade do Sul de Santa Catarina, 2010. p. 1-11.

PEREIRA, V. W.; SCLIAR-CABRAL, L. Compreensão de textos e consciência textual: caminhos para o ensino nos anos iniciais. Florianópolis: Insular, 2012. 
SCLIAR-CABRAL, Leonor. Processamento bottom-up na leitura. Veredas on-line Psicolinguística, Juiz de Fora, p. 24-33, 2/2008. Acesso em:

<http://www.ufjf.br/revistaveredas/files/2009/12/artigo02.pdf>. Acesso em: 22 maio 2011.

SCLIAR-CABRAL, Leonor. Processamento da leitura: recentes avanços das neurociências. In: PEREIRA, V. W.; COSTA, J. C. da (Orgs.). Linguagem e cognição: relações interdisciplinares. Porto Alegre: EDIPUCRS, 2009. p. 49-60.

SMITH, Frank. Compreendendo a leitura: uma análise psicolinguística da leitura e do aprender a ler. Porto Alegre: Artes Médicas, 2003.

SPINILLO, A. G.; MOTA, M. M. P. E. da; CORREA, J. Consciência metalinguística e compreensão da leitura: diferentes facetas de uma relação complexa. Educar em Revista. Curitiba, n. 38, p. 157-171, set./dez. 2010.

TEIXEIRA, João Fernandes. A Teoria da consciência de David Chalmers. Psicologia (USP), v. 8, n. 2, São Paulo 1997. Acesso em:

$<$ http://www.scielo.br/scielo.php?pid=S0103-

5641997000200006\&script=sci_arttext>. Acesso em: 23 maio 2011. 